\title{
PENGGUNAAN MACAM PUPUK DAN BENTUK APLIKASINYA TERHADAP PERTUMBUHAN BIBIT KELAPA SAWIT DI PEMBIBITAN UTAMA
}

(Wide use kinds and application methods of fertilizer forms on the growth of oil palm seedlings in the Main Nursery)

\author{
Nurseha, Danner Sagala, Antonius Dalle \\ Fakultas Pertanian Universitas Prof. Dr. Hazairin,SH Bengkulu
}

\begin{abstract}
The goal of this research was to know the effect of kinds and application methods of fertilizer on oil palm in main nursery.. The materials, used were Oil Palm Tenera Variety, Blitz Fertilizer and Mutiara Fertilizer. The experiment design was completely randomized design with 8 treatments in 5 replications. The treatment were fertilizer kinds and the application methods consisted of granular formed mutiara fertilizer, dissolved mutiara fertilizer, granular formed blitz fertilizer by $50 \%$ mutiara fertilizer dosage, dissolved blitz fertilizer by $50 \%$ mutiara fertilizer dosage, granular formed blitz fertilizer by $100 \%$ mutiara fertilizer dosage, dissolved blitz fertilizer by $100 \%$ mutiara fertilizer dosage, granular formed blitz fertilizer by $150 \%$ mutiara fertilizer dosage, dissolved blitz fertilizer by $150 \%$ mutiara fertilizer dosage. Mutiara fertilizer dosage were 10 grams/seedling for 5 month old, 15 grams/seedling for 6 month old and 15 grams/seedling for 7 month old. Measured variable were plant height, the girth of the stem and midrib number. The results showed that the use of blitz fertilizer by $100 \%$ mutiara fertilizer dosage with dissolved application gave the best growth in oil palm seedlings in the main nursery.

Keywords: Oil palm, Blitz fertilizer, Mutiara fertilizer, Main nursery, Fertilizer application.
\end{abstract}

\section{PENDAHULUAN}

Kelapa Sawit (Elaeis guineensis Jacg) berasal dari Afrika Barat, namun dapat dikembangkan di luar daerah asalnya, termasuk di tujuh negara produsen terbesarnya yakni: Malaysia, Indonesia, Nigeria, Pantai Gading, Colombia, Thailand, dan Papua Nugini (Fauzi, dkk.,2000). Kelapa Sawit merupakan komoditas perkebunan unggulan dan utama di Indonesia. Produk utama kelapa sawit adalah minyak sawit daging buah yang dikenal denagn Crude Palm Oil (CPO) dan minyak inti sawit yang memiliki nilai ekonomis tinggi dan menjadi salah satu penyumbang devisa negara yang terbesar dibandingkan dengan komoditas perkebunan lainnya. Pada tahun 2008 luas areal perkebunan kelapa sawit mencapai 7.363.847 ha atau meningkat $77,1 \%$ dari tahun 2000 yang hanya $4.158,077$ ha. Rata-rata roduktivitas kelapa sawit Indonesia selama periode 2003 - 2009 adalah sebesar 3,72 ton/ha (Fauzi, dkk., 2012). Pada tahun 2011 produksi kelapa sawit naik mencapai 23,5 juta ton dan tahun 2012 mencapai 25 juta ton dengan luas areal 8,2 juta ha. (Buku Statistik Perkebunan, Direktorat Jenderal Perkebunan, 2013).

Perkembangan perkebunan ini menyebabkan ketersediaan lahan subur semakin sulit sehingga lahan marjinal tetap digunakan untuk pengembangan perkebunan. Pemanfaatan lahan marjinal memerlukan perhatian yang mendalam pada pembibitan, pengembangan perkebunan, dan pengelolaan lapangan, serta penanganan penggunaan sumber daya (lahan, tenaga kerja, alat dan bahan) yang tepat (Rankine dan Fairhurst, 1998). Kartika (2000) menyatakan bahwa upaya peningkatan produksi dapat dilaksanakan dengan menerapkan cara budidaya yang 
lebih intensif termasuk penyediaan bibit yang berkualitas dan penggunaan pupuk yang baik, tepat dan ramah lingkungan.

Pupuk Majemuk Padat (PMP) blitz berbentuk briket dibuat di pabrik dan mengandung unsur karbon aktif yang tinggi yang berasal dari bahan-bahan organik sehingga dapat memperbaiki struktur tanah dan sifat - sifat fisika tanah. Hal ini dapat memudahkan akar untuk berkembang dan menyerap unsur hara yang terikat dalam ikatan karbon, sehingga tanaman dapat tumbuh subur dan berproduksi lebih memperbaiki struktur tanah secara bertahap, disesuaikan dengan kondisi agroekosistem, karakteristik komoditi, kandungan unsur hara dalam tanah, keadaan fisika dan kimiawi tanah, serta target pencapaian produksi dengan melihat fisiologi tanaman yang menjadi faktor utama pada penentuan komposisi dan dosis (Kartika, 2000).

Ada beberapa keunggulan PMP blitz antara lain komposisi hara makro dan mikro sebanyak 13 unsur hara (Nitrogen, Phospor, Kalium, Calsium, Sulfur, Magnesium, Besi, Tembaga, Mangan, Seng, khlorin, Boron, dan Molybden), ketepatan komposisi unsur hara dan dosis disesuaikan dengan komoditi, lebih dari 90\% terserap tanaman sehingga dapat menghemat dosis pemupukan, aplikasi pemupukan tidak terghantung cuaca, dapat meningkatkan produksi antara $10 \%$ $30 \%$, cocok untuk lahan yang sering terkena banjir ataupun tanah miring yang mudah terkena erosi, berat satu briket dapat diatur sesuai kebutuhan (Kartika, 2000). PMP blitz pada umumnya digunakan pada perkebunan kelapa sawit sehingga informasi mengenai penggunaan PMP blitz pada pembibitan masih terbatas oleh karena itu perlu dilakukan penelitian mengenai berbagai macam pupuk dan cara aplikasi pada pembibitan utama.

\section{BAHAN DAN METODE}

Penelitian ini dilaksanakan di Desa Arga Jaya Kec. Air Rami Kab. Mukomuko. Waktu penelitian akan dimulai dari tanggal 20 September 2012 sampai tanggal 5 November 2012. Bahan yang akan digunakan dalam penilitian ini adalah: Bibit Kelapa Sawit varietas Tenera , PMP Blitz (16.7.7), Mutiara NPK Mg Cao (16. 16. 16. 1,5. 5), air. Alat yang digunakan adalah: Ember, Sarung tangan, Timbangan gula, Takaran, Meteran. Percobaan ini akan menggunakan Rancangan Acak Lengkap (RAL) faktor tunggal. Delapan perlakuan macam pupuk dengan aplikasi granular dan dilarutkan yang dicobakan pada bibit kelapa sawit di pembibitan utama. Masing-masing perlakuan diulang 5 kali, dengan demikian jumlah satuan percobaan adalah 40 satuan percobaan. Macam perlakuan tersebut adalah:

P1 = Pupuk NPK mutiara, aplikasi granular

P2 = Pupuk NPK mutiara, aplikasi dilarutkan

P3 = Pupuk blitz 50\% dosis NPK mutiara, aplikasi granular

P4 = Pupuk blitz 50\% dosis NPK mutiara, aplikasi dilarutkan

P5 = Pupuk blitz 100\% dosis NPK mutiara, aplikasi granular

P6 $=$ Pupuk blitz 100\% dosis NPK mutiara, aplikasi dilarutkan

P7 $=$ Pupuk blitz $150 \%$ dosis NPK mutiara, aplikasi granular

P8 $=$ Pupuk blitz 150\% dosis NPK mutiara, aplikasi dilarutkan.

Jadwal dan dosis pemupukan bibit kelapa sawit di pembibitan utama seperti dijelaskan pada Tabel 1.

Data yang diperoleh diuji dengan uji Fisher (F), bila uji $F$ menunjukkan pengaruh nyata maka dilanjutkan dengan uji Duncant's Multiple Range Test (DMRT) pada taraf uji 0.05. Penelitian ini berakhir pada umur bibit sawit 7 bulan. Bibit sawit akan diambil dari kebun bibit masyarakat di Desa Arga Jaya . Bibit sawit yang digunakan dalam penelitian ini adalah bibit sawit yang telah berumur 5 (lima) bulan. Jarak antar polibag adalah 
$90 \times 90 \mathrm{~cm}$ jumlah bibit yang digunakan adalah 40 batang. Pupuk akan diberikan pada pagi hari seperti perlakuan diatas, pada saat umur bibit 5 bulan, 6 bulan dan terakhir pada umur 7 bulan. Pemeliharaan meliputi penyiraman dan pengendalian gulma. Penyiraman akan dilakukan pada pagi dan sore hari bila tidak hujan. Pengendalian gulma akan dilakukan dengan mencabut gulma yang tumbuh dalam polibag dan galangan antar polibag.

Pengamatan awal akan dilakukan sebelum perlakuan dan pengamatan lanjutan setiap 2 minggu sesudah dilakukan perlakuan. Peubah yang diamati adalah:

1. Pertambahan tinggi tanaman (cm)

Pengukuran pertambahan tinggi tanaman akan dilakukan dengan mengukur tinggi tanaman awal dan tinggi tanaman akhir penelitian dengan menggunakan meteran. Selisih antara tinggi tanaman akhir dan tinggi tanaman awal adalah pertambahan tinggi tanaman. Tinggi tanaman diukur mulai dari leher akar sampai ujung daun tertinggi.

2. Pertambahan lingkar batang $(\mathrm{cm})$

Pertambahan lingkar batang akan diukur dengan cara mengukur lingkar batang awal dan lingkar batang akhir penelitian dengan menggunakan meteran. Selisih antara lingkar batang akhir dan lingkar batang awal adalah pertambahan lingkar batang. Lingkar batang diukur pada bongkol diatas leher akar.

3. Pertambahan pelepah (helai)

Pertambahan pelepah akan diukur dengan menghitung jumlah pelepah awal dan jumlah pelepah diakhir penelitian. Selisih antara jumlah pelepah akhir dan jumlah pelepah awal adalah pertambahan pelepah.

\section{HASIL DAN PEMBAHASAN}

Macam pupuk dan bentuk aplikasinya berpengaruh sangat nyata terhadap semua peubah yang diamati. Hal ini menunjukkan bahwa perlakuan macam pupuk dan bentuk aplikasinya mempengaruhi pertumbuhan bibit kelapa sawit di pembibitan utama (tabel 2).

\section{Pertambahan tinggi tanaman}

Pemberian NPK mutiara sesuai tabel 1 baik diaplikasi secara granular (P1) maupun dilarutkan (P2) berbeda tidak nyata. Demikian juga dengan perlakuan PMP blitz yang diberikan 50\% dosis NPK mutiara baik itu aplikasi granular (P3) maupun dilarutkan (P4) berbeda tidak nyata, namun berbeda nyata dengan perlakuan (P1) dengan Pemberian pupuk PMP blitz $100 \%$ dosis NPK mutiara aplikasi granular (P5) dan berbeda tidak nyata dengan pemberian PMP blitz 150\% dosis NPK Mutiara aplikasi granular (P7) dan aplikasi dilarutkan (P8) sesuai tabel 1. Perlakuan terbaik adalah pada pemberian PMP blitz sesuai dosis pada tabel 1 dengan aplikasi dilarutkan (P6) seperti pada (Tabel 3) dibawah ini.

\section{Pertambahan lingkar batang}

Pemberian pupuk NPK mutiara aplikasi granular (P1) berbeda nyata dengan aplikasi dilarutkan (P2), namun perlakuan $\mathrm{P} 3$ berbeda tidak nyata dengan P1. Pemberian PMP blitz 100\% dosis NPK mutiara aplikasi dilarutkan (P6) memberikan hasil lingkar batang tertinggi, namun berbeda tidak nyata dengan perlakuan P7 dan berbeda nyata dengan perlakuan lainnya.

\section{Pertambahan pelepah}

Pemberian pupuk NPK mutiara aplikasi granular (P1) maupun aplikasi dilarutkan (P2), berbeda tidak nyata, namun perlakuan tersebut berbeda nyata dengan perlakuan lainnya. Pemberian PMP blitz $100 \%$ dosis NPK mutiara dengan aplikasi dilarutkan (P6) dan pemberian PMP blitz $150 \%$ dosisi NPK mutiara aplikasi dilarutkan (P8) memberikan hasil lingkar batang tertinggi, namun berbeda tidak nyata dengan perlakuan (P7) dan berbeda nyata dengan perlakuan lainnya. 
Hasil penelitian menunjukkan bahwa perlakuan pengaruh berbagai macam pupuk dan bentuk aplikasinya berpengaruh sangat nyata terhadap semua peubah yang diamati. Hasil uji DMRT terlihat bahwa perlakuan pemberian pupuk NPK mutiara baik secara granular maupun dilarutkan berbeda tidak nyata pada taraf uji DMRT 0,05. Hal ini menunjukkan bahwa proses pelarutan pupuk NPK Mutiara tidak membuat serapan unsur hara lebih tersedia dan lebih banyak terserap oleh bibit kelapa sawit. Aplikasi dengan dilarutan diduga membuat pupuk lebih cepat tersedia, tetapi pupuk lebih mudah juga hilang karena penguapan, terikat oleh misel tanah sehingga tidak tersedia dan juga tercuci (leaching) dan denitrifikasi. Hal ini sesuai dengan pendapat Fauzi dkk., (2000) bahwa pupuk $\mathrm{N}$ mudah tercuci (leaching), denitrifikasi dan nitrifikasi hilang karena perubahan bentuk ammonia menjadi gas $\mathrm{NO}_{2}$ dan $\mathrm{N}_{2}$ dan penguapan (volatilisasi). Sedangkan unsur $\mathrm{K}$ mudah tercuci bila hujan atau penyiraman sehingga tidak tersedia bagi tanaman. Lebih lanjut dijelaskan oleh Kartika (2000) bahwa kelemahan pupuk kimiawi antara lain: (a) kehilangan akibat penguapan berkisar antara 10\% - 20\%; (b) kehilangan akibat Leaching 5\% - 10\%; (c) kehilangan akibat erosi kedalam tanah $15 \%$ - 30\%; (d) jumlah pupuk yang diserap oleh tanaman hanya berkisar antara 40\% - 70\%; (e) penggunaan pupuk kimia dapat merusak struktur tanah; (f) ketersedian pupuk kimia berlaku sama untuk semua jenis tanaman baik jenis maupun konsentrasi kandungan unsur.

Hasil uji perbandingan berganda Duncant memperlihatkan bahwa perlakuan (P6) yaitu Pemberian PMP blitz $100 \%$ dosis NPK mutiara dengan aplikasi dilarutkan memberikan pertumbuhan bibit kelapa sawit terbaik. Hal ini menunjukkan bahwa pemberian PMP blitz $100 \%$ dosis NPK mutiara memberikan pertumbuhan bibit sawit terbaik dibandingkan dengan pemberian 50\% dosis NPK mutiara maupun $150 \%$ dosis
NPK mutiara. SIPEF(1999) menyebutkan bahwa tanaman memerlukan unsur hara sesuai kapasitasnya untuk pertumbuhan optimal. Apabila dosis yang diberikan kurang maka akan terhambat pertumbuhannya dan bila berlebih maka pupuk akan mubazir karena tidak terserap bagi tanaman bahkan dapat merusak selsel tanaman (plasmolisis). Ditambahkan oleh kartika (2000) bahwa pemupukan harus memperhatikan ketepatan komposisi hara dan dosis disesuaikan dengan komoditi. Tabel diatas dan grafik pada lampiran juga memperlihatkan bahwa pemberian PMP blitz secara terlarut lebih baik dari granular. Hal ini diduga disebabkan bila dalam kondisi terlarut unsur hara yang terkandung dalan PMP blitz lebih mudah tersedia dan terserap bagi tanaman. Sedangkan dalam bentuk granular lebih lambat tersedia karena perlu proses pelarutan terlebih dahulu.

PMP blitz jauh lebih baik dibandingkan dengan pupuk NPK mutiara untuk pertumbuhan bibit kelapa sawit. Hal ini bisa dilihat pada Tabel 3, 4 dan 5 diatas. diduga penyebabnya adalah komposisi hara makro dan mikro lebih banyak dibandingkan pupuk kimia majemuk, Unsur hara tersedia dalam bentuk anion kation sehingga mudah diserap, mempunyai hormon ZPT sehingga memudahkan penyerapan dan mempercepat pertumbuhan. Hal ini sesuai dengan pendapat Kartika (2000) yang mengatakan bahwa: (a) PMP blitz mengandung unsur hara makro dan mikro sebanyak 13 unsur yaitu: Nitrogen, Phosphor, Kalium, Kalsium, Sulfur, Magnesium, Besi, Tembaga, Mangan, Seng, Khlorin, Boron, dan Molybdenum; (b) ketepatan komposisi hara dan dosis disesuaikan dengan komoditi; (c) mudah terurai dan tidak meninggalkan residu kimia; (d) unsur hara tersedia dalam bentuk anion kation sehingga mudah diserap; (e) mengandung hormon ZPT sehingga memudahkan penyerapan, didapat efisiensi pemupukan, dan mempercepat pertumbuhan; 
Peningkatan produksi sampai minimal $10 \%$; (g) tersedia dalam bentuk yang mudah terdisosiasi dalam air; dan (h) efisiensi penyerapan unsur hara yang tinggi karena mengandung enzim aktivasi sel daun.

\section{KESIMULAN DAN SARAN}

Kesimpulan:

1. Perlakuan macam pupuk dan bentuk aplikasinya berpengaruh sangat nyata terhadap pertumbuhan bibit kelapa sawit di pembibitan utama.

2. Pemberian PMP blitz sesuai dosis NPK mutiara aplikasi dilarutkan memberi pertumbuhan terbaik pada bibit kelapa sawit di pembibitan utama.

3. PMP blitz mampu menggantikan NPK mutiara.

Saran

1. Disarankan untuk memberikan PMP blitz sesuai dosis NPK mutiara dengan aplikasi dilarutkan untuk memperoleh pertumbuhan terbaik pada bibit kelapa sawit di pembibitan utama umur 5-7 bulan. Dosis NPK mutiara tersebut adalah umur 5 bulan 10 gr/bibit, umur 6 bulan $15 \mathrm{gr} / \mathrm{bibit}$ dan umur 7 bulan $15 \mathrm{gr} / \mathrm{bibit}$.

2. Perlu penelitian lanjut untuk pemupukan bibit kelapa sawit dengan PMP blitz pada umur 1-5 bulan, 7 bulan sampai siap tanam serta untuk tanaman di areal kebun.

\section{DAFTAR PUSTAKA}

BALITBANGTAN (Badan Penelitian dan Penegembangan Pertanian). 2011. Prospek Pertanian Organik di Indonesia. Jakarta.

Direktorat Jenderal Pajak Statistik Perkebunan. 2012. Produksi, Luas Areal dan Produktivitas Perkebunan di Indonesia. Jakarta.
Fauzi, Y. E. Widyawati., I. Satyawibawa., R. H. Paeru. 2000. Kelapa Sawit. Penebar Swadaya, Jakarta

Kartika, D. 2000. Pemanfaatan Pupuk Organik di Perkebunan Kelapa Sawit. Tidak di Publikasikan, Jakarta.

Nasution, U. 1986. Gulma dan Pengendaliannya di Perkebunan Karet Sumatera Utara dan Aceh. Pusat Penelitian dan Pengembangan Perkebunan Tanjung Morawa. Tanjung Morawa.

Rankine, F. 1998. Pembibitan Kelapa Sawit. Pusat Penelitian Kelapa Sawit. Medan.

Rankine, F. 1998. Tanaman Belum Menghasilkan Kelapa Sawit. Pusat Penelitian Kelapa Sawit. Medan.

Rankine, F. $1998^{\mathrm{b}}$. Tanaman Menghasilkan Kelapa Sawit. Pusat Penelitian Kelapa Sawit. Medan.

SIPEF (Society International Plantation Et The Finance).1996. Agricultural Manual General Section PT. Tolan Tiga Indonesia SIPEF Group. Medan.

SIPEF (Society International Plantation Et The Finance). 1997. Agricultural Manual Oil Palm Section PT. Tolan Tiga Indonesia SIPEF Group. Medan.

Sugito, J. 1997. Kelapa Sawit, Usaha Budidaya, Pemanfaatan Hasil, dan Aspek Pemasaran. Penebar Swadaya. Jakarta.

Pamin, K. 1997. Gejala Defisiensi Hara dan Kelainan pada Tanaman Kelapa Sawit (Elaeis guineensis, Jacg). Pusat Penelitian Kelapa Sawit. Medan.

Permatasari, RGI. 2012. Produksi Kelapa Sawit. Diakses dari ( www.okzone.com) pada [01 April 2013]. 
Tabel 1. Jadwal dan Dosis Pemupukan Bibit Kelapa Sawit di Pembibitan Utama (gr/bibit)

\begin{tabular}{|c|c|c|c|r|r|r|r|r|r|}
\hline Umur & Aplikasi/ & \multicolumn{7}{|c|}{ Jenis Perlakuan (gr/bibit) } \\
\cline { 2 - 10 } (Bulan) & bln (Kali) & P1 & P2 & P3 & P4 & P5 & P6 & P7 & P8 \\
\hline 5 & 1 & 10 & 10 & 5 & 5 & 10 & 10 & 15 & 15 \\
\hline 6 & 1 & 15 & 15 & 7,5 & 7,5 & 15 & 15 & 22,5 & 22,5 \\
\hline 7 & 1 & 15 & 15 & 7,5 & 7,5 & 15 & 15 & 22,5 & 22,5 \\
\hline
\end{tabular}

Tabel. 2.Rekapitulasi Hasil Sidik Keragaman Pengaruh Macam Pupuk dan Bentuk Aplikasinya.

\begin{tabular}{|l|c|}
\hline \multicolumn{1}{|c|}{ Peubah Yang Diamati } & F. Hitung \\
\hline Pertambahan Tinggi Tanaman & $5,34^{* *}$ \\
Pertambahan Lingkar Batang & $4,24^{* *}$ \\
Pertambahan Pelepah & $10,54^{* *}$ \\
\hline
\end{tabular}

Keterangan: ** Berpengaruh sangat nyata

Tabel 3. Pengaruh Berbagai Macam Pupuk dan Bentuk Aplikasinya Terhadap Pertambahan Tinggi Bibit Sawit di Pembibitan Utama.

\begin{tabular}{|l|c|}
\hline \multicolumn{1}{|c|}{ Macam Pupuk dan Bentuk Aplikasinya } & $\begin{array}{c}\text { Pertambahan } \\
\text { Tinggi } \\
\text { Bibit (cm) }\end{array}$ \\
\hline P1 = Pupuk NPK mutiara, aplikasi granular & $16,60 \mathrm{a}$ \\
P2 = Pupuk NPK mutiara, aplikasi dilarutkan & $18,60 \mathrm{ab}$ \\
P3 = Pupuk blitz 50\% dosis NPK mutiara, aplikasi granular & $20,80 \mathrm{~b}$ \\
P4 = Pupuk blitz 50\% dosis NPK mutiara, aplikasi dilarutkan & $20,40 \mathrm{~b}$ \\
P5 = Pupuk blitz 100\% dosis NPK mutiara, aplikasi granular & $26,40 \mathrm{c}$ \\
P6 = Pupuk blitz 100\% dosis NPK mutiara, aplikasi dilarutkan & $34,00 \mathrm{~d}$ \\
P7 = Pupuk blitz 150\% dosis NPK mutiara, aplikasi granular & $28,80 \mathrm{c}$ \\
P8 = Pupuk blitz 150\% dosis NPK mutiara, aplikasi dilarutkan & $28,80 \mathrm{c}$ \\
\hline
\end{tabular}

Keterangan: angka angka yang diikuti oleh huruf yang sama dalam satu kolom berbeda tidak nyata pada taraf uji DMRT 0,05.

Tabel 4. Pengaruh Berbagai Macam Pupuk dan Bentuk Aplikasinya Terhadap Pertambahan Lingkar Batang Bibit Kelapa Sawit di Pembibitan Utama.

\begin{tabular}{|l|c|}
\hline \multicolumn{1}{|c|}{ Macam Pupuk dan Bentuk Aplikasinya } & $\begin{array}{c}\text { Pertambahan } \\
\text { Lingkar } \\
\text { Batang }(\mathrm{cm})\end{array}$ \\
\hline P1 = Pupuk NPK mutiara, aplikasi granular & $3,90 \mathrm{a}$ \\
P2 = Pupuk NPK mutiara, aplikasi dilarutkan & $5,30 \mathrm{~b}$ \\
P3 = Pupuk blitz 50\% dosis NPK mutiara, aplikasi granular & $4,10 \mathrm{ab}$ \\
P4 = Pupuk blitz 50\% dosis NPK mutiara, aplikasi dilarutkan & $5,40 \mathrm{~b}$ \\
P5 = Pupuk blitz 100\% dosis NPK mutiara, aplikasi granular & $6,20 \mathrm{c}$ \\
P6 = Pupuk blitz 100\% dosis NPK mutiara, aplikasi dilarutkan & $6,80 \mathrm{~d}$ \\
P7 = Pupuk blitz 150\% dosis NPK mutiara, aplikasi granular & $6,60 \mathrm{~cd}$ \\
P8 = Pupuk blitz 150\% dosis NPK mutiara, aplikasi dilarutkan & $6,00 \mathrm{bc}$ \\
\hline
\end{tabular}

Keterangan: angka angka yang diikuti oleh huruf yang sama dalam satu kolom berbeda tidak nyata pada taraf uji DMRT 0,05 . 
Tabel 5. Pengaruh Berbagai Macam Pupuk dan Bentuk Aplikasinya Terhadap Pertambahan Pelepah Bibit Kelapa Sawit di Pembibitan Utama.

\begin{tabular}{|l|c|}
\hline \multicolumn{1}{|c|}{ Macam Pupuk dan Bentuk Aplikasinya } & $\begin{array}{c}\text { Pertambahan } \\
\text { Pelepah } \\
\text { (helai) }\end{array}$ \\
\hline P1 = Pupuk NPK mutiara, aplikasi granular & $2,00 \mathrm{a}$ \\
P2 = Pupuk NPK mutiara, aplikasi dilarutkan & $2,40 \mathrm{a}$ \\
P3 = Pupuk blitz 50\% dosis NPK mutiara, aplikasi granular & $3,00 \mathrm{~b}$ \\
P4 = Pupuk blitz 50\% dosis NPK mutiara, aplikasi dilarutkan & $3.00 \mathrm{~b}$ \\
P5 = Pupuk blitz 100\% dosis NPK mutiara, aplikasi granular & $3,80 \mathrm{c}$ \\
P6 = Pupuk blitz 100\% dosis NPK mutiara, aplikasi dilarutkan & $5,60 \mathrm{~d}$ \\
P7 = Pupuk blitz 150\% dosis NPK mutiara, aplikasi granular & $5,40 \mathrm{~d}$ \\
P8 = Pupuk blitz 150\% dosis NPK mutiara, aplikasi dilarutkan & $5,60 \mathrm{~d}$ \\
\hline
\end{tabular}

Keterangan: angka angka yang diikuti oleh huruf yang sama dalam satu kolom berbeda tidak nyata pada taraf uji DMRT 0,05 . 